\title{
New approaches and strategies for teaching African children initial reading
}

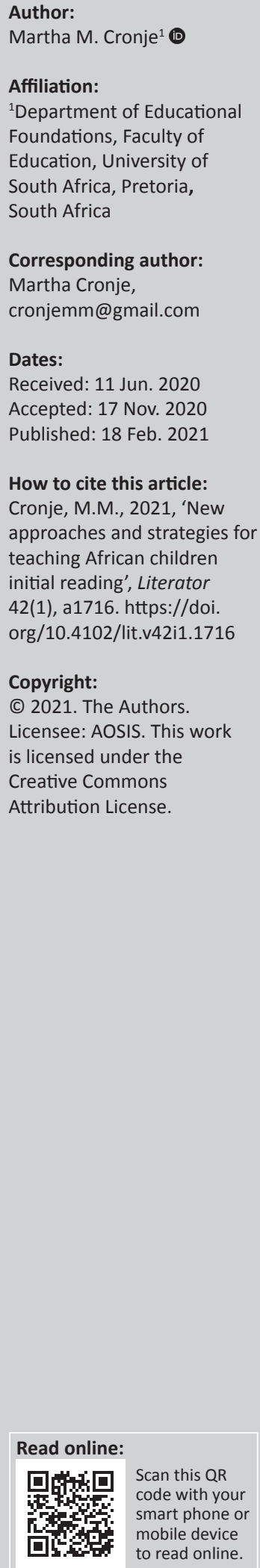

In the 1990s, during investigations at primary schools, the author tested the ability of Grade 2 African children to read, finding that about $80 \%$ of them could read. However, for the past 15 years the author has found that only about $20 \%$ of Grade 2 African learners can read, as also confirmed by the Progress in International Reading Literacy Study (PIRLS) which in 2016 found that about $80 \%$ of Grade 4 children do not have basic reading skills, indicating a reading crisis in South Africa. For this article pedagogic reasons for the reading crisis, and possible solutions, were sought by means of a literature search regarding: the reading crisis, its causes and consequences; approaches to initial reading and their suitability to African languages; and departmental prescriptions for Grade 1. Two pedagogic reasons for the crisis were found: (1) The approaches to initial reading in use are not suitable for African children and African languages and (2) The Grade 1 Lesson Plan (instead of the Government's CAPS) used for teaching English second language, confuses children with written English, with another set of letter sounds, so that most cannot learn to read. This article proposes a new curriculum for Grade 1, and addresses the following gaps in the literature: it points out particulars about African languages that indicate the phonics approach to initial reading unsuitable for African children, while advocating the syllabic approach, long unknown and/or misjudged. This article is also significant for pointing out the injustice done to children who must do initial reading in two languages simultaneously.

Keywords: African languages; approaches to teaching reading; educational documents; initial reading; ReSEP document; South Africa's reading crisis; syllabic reading approach.

\section{Introduction}

\section{South Africa's reading crisis}

It is widely known for more than 10 years that South Africa (SA) has a reading crisis. Most children fail to learn to read well and with understanding in both the Home Language (HL) and English Second Language (ESL), although nearly all learners need ESL as education medium from Grade 4 onwards. The crisis is indicated amongst others by the Progress in International Reading Literacy Study (PIRLS), in which the South African children participated in 2006, 2011 and 2016. Concerning the PIRLS 2016, Howie et al. (2017:11) indicated that less than $20 \%$ of African Grade 4 learners have reached the $40 \%$ mark, compared to $96 \%$ learners who managed to do so in 49 other countries. This means that less than $20 \%$ of African learners have 'basic reading skills' in Grade 4, although tested in their home languages. The fact that in the 1990 s about $80 \%$ of Basotho children learnt to read their HL in Grade 1 (Cronje 1997:77, 89) indicates that the main reason for the poor literacy levels must not be ascribed to the inability of African children to learn reading, or to teachers who cannot teach reading.

The PIRLS tests are taken in the HL, as the value of doing initial reading in the HL, rather than in a second language, is globally acknowledged. Mlachila and Moeletsi (2019:35) wrote that research literature indicates clearly that learners will achieve better results if they learn in the HL. When a child can read the HL, those skills can be transferred to reading ESL, although more skills are needed. Probert and De Vos (2016:9) investigated types of transfer, concluding that it is easier to transfer reading skills that are learnt using a transparent writing system (e.g. an African language) rather than an opaque orthography (such as English).

However, children who cannot read well and with understanding in the HL have little to transfer to ESL. Draper and Spaull (2015) conducted tests in 214 rural schools on the ability to 
read and understand ESL. The Oral Reading Fluency (ORF) of 1772 Grade 5 ESL learners was tested and was matched to their comprehension test scores, finding that children who read too slowly could not understand what they read. Of the 1772 Grade 5 learners, $41 \%$ were reading less than 40 words correct per minute (WCPM), with an average of 17 WCPM, and could be considered 'non-readers' in English (Draper \& Spaull 2015:56-72).

Inability to read well and with understanding can have devastating consequences for the majority of South Africa's children and also for the country as a whole. Spaull and Hoadley (2017:77) said that if children can read and learn independently, they are enabled to learn considerably more than their teachers may present, adding that reading can lead to abstract thinking. However, Van der Berg (2015:14) said that according to the Annual National Assessment (ANA), most children are so far behind by the middle of primary school that not many opportunities are still open to them. Mlachila and Moeletsi (2019:5) mentioned that education contributes greatly to economic growth, as it determines workers' productivity. By reducing poverty and inequality, education can advance the prosperity of a nation. They added that it is likely that South Africa's generally low quality of education has contributed to slow economic growth.

Perry (2009:57-60), referring to Bamgbose, mentioned a further possible consequence of reading failure, saying that literacy is a 'politically loaded activity' and can be used to control and dominate. Bamgbose (2000) suggested that language policy serves to open or close doors for people in Africa, as it has the ability to produce two distinct classes: the included (those who know the official language offering political and economic power) and the excluded (who lack knowledge of the official language). He mentioned that schools in Africa have the authority to exclude in many ways.

\section{Causes of the reading crisis}

Much has been written about factors contributing to the reading crisis which fall outside the scope of this article. Fleisch (2008) asserted that the reasons for the crisis are complicated and cut across economics, politics, health and other sectors. However, he added that in the first place, success with reading depends on what happens in classrooms between learners and teachers (Fleisch 2008:102).

A possible pedagogic cause for the failure to learn to read is that approaches to initial reading are used that are not suitable for African children learning African languages. The author has not found in the literature any study comparing the effect of different approaches to initial reading on the ability of African children to learn to read. However, different reading approaches are used now than when learners were tested in the 1990s, when on average about $80 \%$ of Grade 1 learners learnt to read in a number of Welkom township schools.
There is a second possible pedagogic cause for the failure to learn to read that is not mentioned in the literature: the fact that non-English children have to learn to read in two languages simultaneously, the HL and ESL. This circumstance is largely because of a Department of Basic Education (DBE) 'Lesson Plan' which Grade 1 teachers in some provinces have to use for teaching ESL. This thick Lesson Plan (about 200 pages) is in conflict with the government's Curriculum Assessment Policy Statement (CAPS) for ESL in the Foundation Phase (Grades 1-3) (DBE 2012). The CAPS for English First Additional Language (EFAL) instructs that in Grade 1 children should read only in the HL whilst learning ESL only orally. It warns (DBE 2012a, CAPS for EFAL):

It is important that in Grade 1 children develop a strong oral foundation in their additional language. Otherwise they will not understand the words they are decoding in English in Grade 2 ... Children are often able to decode in their additional language, but unable to understand what they read. (p. 2)

However, the Lesson Plan prescribes much written English from Week 3 in Grade 1. This may be a key factor in the failure to learn reading, as having to cope with two sets of letter sounds may be very confusing to Grade 1 children. Most African children struggle to remember the different sounds of the five vowels, which to them seem to sound very similar. They can chant a, e, i, o, u - but cannot read them when single or mixed. They cannot cope with a large second set of letter sounds.

\section{Aim and objectives of this study}

The main goal of this article is that effective ways should be found to teach reading to Grade 1 African learners. Therefore approaches to initial reading are investigated, and particulars of African languages are discussed, in a search for the best approaches and strategies for initial reading in African languages. Investigation of the current teaching practices is also needed, to oppose traditions and practices which may be counter-productive. The worst current practice is that much written ESL is given from early in Grade 1. Not only are children confused by two writing codes, but they can also not learn much ESL with such a formal approach. Unfortunately an explanation for the latter from Second Language Acquisition research falls outside the scope of this article.

This article also discusses both the CAPS for Home Languages and the ReSEP document for training Foundation Phase teachers, as far as initial reading is concerned. These documents carry the prescriptions teachers must follow when teaching reading in Grade 1. Finally, this article will present a proposal for a partial new curriculum for Grade 1, as well as a review of an intervention implemented in North West Province since 2015. Reference to the results of the said intervention may indicate a need for more attempts to renew Grade 1 teaching. 
The overarching goal is that education for the poor should be improved in its entirety, because stark injustice is done to poor children who cannot attend good English crèches, and then also fail to learn basic reading skills and ESL in Grade 1.

\section{Method}

The main methods used for the writing of this article is a literature study and years of practical experience as a volunteer for teaching initial reading in township schools for African children. Therefore, this article mainly reports on a literature search regarding approaches to initial reading and their suitability to African languages, together with a critique of educational prescriptions for Grade 1. It also reports on observations of teaching in Grade 1 classrooms, previously and up to 2020.

A new methodology for teaching initial reading in Grade 1 is also proposed in this article, a methodology that should have been tested in Grade 1 classrooms in 2020 by a Unisa second year PhD student, had the coronavirus not intervened.

\section{Approaches to teaching initial reading}

Initial reading is all important, but the poor results of reading tests seem to indicate that the methods and strategies presently used for teaching reading to African children lead to failure.

\section{The alphabet and phonics approaches}

The only children's readers in the United States up to 1820 contained the alphabet, a set of syllables and prayers. The 'alphabet method' meant children spelt aloud the syllables and then spelt and recited each word of a prayer (Barry 2008).

The phonics approach followed when people realised that children should rather use letter sounds than letter names. Spaull and Pretorius (2019:12) explained that decoding relies on several sub-skills such as phonemic awareness (identifying each sound in a spoken word) and knowledge of letter sounds. Reading well means all these components are managed rapidly. Williams (1998:72) mentioned that phonics has the advantage that learners can read words they have not met before by sounding them.

\section{The whole approach}

Rayner et al. (2002) referred to two variants of this approach to teach reading:

- With the whole-word approach, children learn 'sight words', meaning they memorise 50-100 words and recognise them immediately. The unrelated words are learnt in a given order and children gradually acquire more words. (The author has found that, when combined with phonics, this approach causes Afrikaans children to decode mechanically instead of reading for meaning.)

- The whole-language approach prefers short sentences to unrelated words. Rayner et al. (2002:86) asserted that the goal with this approach is to make reading fun, as it builds on experiences children have with language. Some people even hold that it is not necessary to teach the rules of phonics directly, as letter-sound connections will be learnt by the way. However, research shows that phonics is also important and that combining the whole approach and phonics is worth more than any one of the methods alone.

Williams (1998) maintained that the whole-language approach has the advantage that whole units are recognised rapidly, and consequently, a child's reading can be more similar to the fluent reading of skilled readers, rather than reading letter-by-letter. He mentioned, however, the risk that learners can repeat without comprehending. (A significant problem noticed by the author is that learners just memorise lessons and pretend to read.)

The whole approach, combined with phonics, is prescribed in SA for Grade 1 (CAPS HL 2012b), as this is advantageous for reaching automaticity (recognising words as wholes). It is indicated by research to be the best combination for reading European languages. However, empirical research about this has not been done for African languages, as far as could be discerned. This article only gives answers from a literature search and practical experience.

\section{The syllabic approach}

Only Williams (1998:71) wrote about the syllabic approach, used earlier for reading African languages. It is based on sequences of consonants and vowels such as $k a, k e, k i, k o$, $k u$, which teachers wrote on the board or on charts as basis for activities, for example, making words. This approach is rarely mentioned in recent papers on reading, but referred to by De Vos et al. (2014:14). They mentioned that African teachers seem to have recognised intuitively that an alphabet approach may not be ideal for syllabic languages and taught learners to recognise syllables automatically, rather than phonemes. They added that this method is 'sometimes referred to anecdotally and derogatorily as the "'ba-be-bi-bo" methodology'. (The word 'derogatorily' may explain the silence about this approach.) They acknowledge that this technique is probably a rational response to language structures, 'worthy of more research'. Schaefer and De Vos (2015) did such research, which will be discussed presently.

\section{Onset and rime}

Williams (1998:72) says that this is rather a technique than an approach, because we can break syllables down into initial 
'onsets' and 'rimes', or the rhyming part. Manipulating onsets and rimes in word games help children and may have the same value for English children as the syllabic approach has for African children, according to Williams (1998).

This strategy is much used today, called 'rhyme', and found important for learning to read - for European children. In the ESL Grade 1 Lesson Plan, used also for African children, it is called 'phonics'. The 'phonics' given for Week 3 in Grade 1: cat, hat, fat, sat, rat (mat, pat); for Week 5: hit, sit, lit, kit, fit, pit, bit. For English children, most of these words have meaning, but for children learning ESL, most words are meaningless, which makes a great difference in the value this can have for children learning to read.

\section{Some characteristics of African languages}

Spaull, Pretorius and Mohohlwane (2017:2-4) write that the 'Southern African Bantu languages' are agglutinating languages (morphemes are 'glued' together), with transparent orthographies (writing systems), letters being mapped to sounds one-to-one. They compare it to the opaque orthography of English, where one letter can denote many sounds. (' $A$ ' is pronounced in seven different ways in the half-sentence 'What many baby cats saw in a car...'.) One sound can also be indicated in different ways, for example, 'fat, phase and laugh'. Such an opaque orthography is more difficult to learn to read than an African language.

However, there is information on aspects of these African languages that is not found in the literature, for example, that they have a small number of vowel sounds and that syllables end in vowels with hardly any final consonants. This knowledge has implications for teaching reading in African languages, for example that it makes no sense to use rhyme, and that reading the five vowels correctly is important, as a mistake will probably mean another word and no understanding. Yet, knowing the vowels receives little attention in Grade 1 African classes, as should happen in Grade 1 English classes because of the inconsistent use of English vowels.

\section{The suitability of reading approaches to African languages}

Whilst any approach should be used together with the whole-language approach, as a combination is better than any one approach alone (Rayner et al. 2020), there are indications that the syllabic approach rather than phonics is best for initial reading in African languages. Schaefer and De Vos (2015) performed various tests on phonological awareness using 31 Grade 4 isiXhosa learners. Participants obtained an average of about $90 \%$ on the syllable segmenting and blending tasks, but only $12 \%$ on phoneme segmenting. Two-thirds of those Grade 4 learners had not one correct answer on phoneme segmenting. The authors say we should not assume that African learners can attain phonological awareness the way English learners can.
Responding to the above, it should be explained that there are reasons, not mentioned in the literature, why young African learners should not be expected to say all letter-sounds. They cannot say some letter-sounds the way Europeans do. A language such as isiZulu has only five vowel sounds, meaning a Zulu child can say the letter B, for example, in only five ways: $b a, b e, b i, b o$ and $b u$. The letter B cannot be said without adding a vowel and Europeans add the neutral vowel when they want to say B alone. However, African languages do not have the neutral vowel, and most children, and many teachers, cannot pronounce the letter B with the neutral vowel. Because of the demand that phonics should be taught, some teachers teach the letter B as $b u$, and some Grade 2 learners try to read bana as bu a $n a$, and get no further. (With the syllabic approach bana - children - is simply taught as $b a$ na.) Unvoiced consonants such as $f, p, s$ and $t$ are not difficult to say alone, but are then difficult to hear, something that never happens in African languages because a consonant is always followed by a vowel and vowels are voiced. Because of this, expecting from teachers and learners to say the phonemes may be problematic, except for the vowels and a few consonants which can also function as syllables, for example, $\mathrm{M}$ and $\mathrm{N}$. The practical solution to these problems is to teach African children syllables only, for example, $f a, p a$ and $s a$, rather than $f, p$ and $s$ alone. Furthermore, the fact that syllables end on vowels means that segmenting in syllables is natural and easy, whereas segmenting in phonemes is quite unnatural to African languages.

Regarding the phonics approach, indications that it is not optimal for African learners are to be found in results such as those provided by Spaull et al. (2017:12-16; 23). They wrote about a study undertaken by the Research on Socio-economic Policy (ReSEP) team at Stellenbosch University. The team did a number of tests on 740 Grade 3 African learners; for example on letter-sounds as well as word reading, ORF and oral comprehension. Of the 740 Grade 3 learners assessed, only a quarter could name at least 40 letters correct per minute (LCPM), and the quarter slowest learners scored at most 15 LCPM. Word reading on average was 22 WCPM, and the ORF score was 41 WCPM in Northern Sotho, a disjunctive language with many one-syllable words. All scores were low, including comprehension - although the tests were taken in the HL. The authors wrote that almost the whole group of Grade 3 children read 15\% - 20\% of the letter-sounds they attempted wrongly and conjecture that these results indicate that teachers did not give enough time to teaching phonics systematically.

We may ask if inefficient teaching is the only possible cause for African children scoring poorly in letter-sound tests. Or is one of the factors that they cannot say some of the letter-sounds? Do they need to sound single letters to be able to read, or can they read the consonants in syllables only? This question asked by De Vos et al. (2014:16) is still not answered: '...what is it about the way learners decode in African languages that inhibits or delays automaticity?' Schaefer and De Vos (2015:5) asserted that as sounds and letters are mapped one-to-one in isiXhosa, one can expect 
that Xhosa learners will acquire phonological awareness quickly, as happens with readers of other transparent writing systems. As this is not the case, they speculate that teaching methods are used that are good at developing phonological awareness in English, but not in African languages.

From the above, it can be concluded that the syllabic approach is best for teaching initial reading in African languages, whilst the phonics approach is counter-productive. Yet the phonics approach is prescribed for Grade 1 and is the approach that is used in SA schools.

\section{Observations of reading instruction in African classrooms}

There are not many studies on the way initial reading is taught at African schools. Rule and Land (2017:4-6) wrote that traditionally it was learning letters, linked to sounds and combined to make words, with $n a, n e, n i, n o, n u$ as the basics. In reading assessments, marks were given for pronunciation and fluency. Reading comprehension was not assessed, and the 'focus of meaning-making' was on single words rather than on larger pieces of texts such as paragraphs, or even sentences. What is saddening is that the above is how teachers remember being taught, but it is also the way they teach themselves, with a few changes based on CAPS directions. Spaull and Hoadley (2017:80) also reported on recent classroom-based studies which show that teaching focuses on the whole class rather than on individuals; on decoding rather than on understanding, and on isolated words rather than longer texts.

On investigating literacy practices in Grade 1-4 classrooms in the Limpopo Province, Reeves et al. (2008) reported that classes often read in unison with or without the teacher, and repeat lessons excessively. Few opportunities were given to read individually, and even in Grade 1 'reading aloud together' was the general way to read. During such class reading it was observed that, in more than a third of cases, most learners 'appeared not to be engaged in reading at all' but were merely repeating. The report says that some learners probably did not have any idea as to how the others were reading. Opportunities to read alone often meant only a word or two. The report also says that learners worked very slowly on tasks, and it was estimated that less than half of the Foundation Phase teachers usually covered the curriculum (Reeves et al. 2008:133-139).

Cronje (1997:76-77) wrote that in the 1990s, one method used in Grade 1 was to write three new words below each other and teach them. When individuals could 'read' any one, the teacher was satisfied - ignoring the possibility that learners simply knew the positions of the words. Later lessons consisted mostly of the teacher reading as a model and the whole class repeating, reading a lesson many times over, with certain words learnt for spelling tests. Much attention was given to pronunciation, none to comprehension. The ensuing learning depended mostly on the teacher's dedication, and on average, about $80 \%$ of learners starting
Grade 2 could read easy sentences in the HL. What is disturbing is that for the past 15 years, the author has found in the same province that only about $20 \%$ of learners starting Grade 2 can read.

The above reports indicate that opportunities for individual reading practice are rare, repetition is the main strategy and comprehension is never an objective. To make a difference, a new curriculum will have to address these problems.

\section{Departmental instructions and reading methodology}

To augment the information gleaned from the literature review on how reading is taught currently in Grade 1 classrooms, two educational documents which give instructions regarding reading the HL in Grade 1 will be discussed.

\section{CAPS instructions for the teaching of reading the $\mathrm{HL}$ in Grade 1}

For the Foundation Phase, there is a CAPS document for HL in each of South Africa's 11 official languages. However, each is a translation of the CAPS for English HL, with probably a few things added or removed. Some criticisms on the CAPS for isiXhosa are given below.

According to De Vos et al. (2014:3), the CAPS document demonstrates that authorities know really little about the language aspects of initial reading. They refer to Bikitsha and Katz (2013), whose analysis of the CAPS isiXhosa HL document exposed many irregularities and contradictions, without considering the structure of specific languages. One example is that vowels written as two letters should be taught in Grade 2, although isiXhosa does not have two-letter vowels. Another is that the CAPS says there are 'many ways of spelling words/sounds', whilst isiXhosa has a transparent writing system and does not indicate sounds in multiple ways.

What follows are extracts from the CAPS HL (2012b), with explanations:

The CAPS ... divides the requirements for reading into -

Shared Reading (All reading together, one text per week with activities based on the text. 'On the third, and possibly the fourth day, children read the text themselves ...')

Group Guided Reading (A group of 6-10 children at a time read the text for 10-15 minutes, silently or aloud. The teacher listens to two groups a day, to the individuals, listening once a week to each child in her class).

Paired/Independent Reading (The text of the week read by pairs or alone, repeatedly.)

Phonics (For the first two terms one or two new sounds are taught each week, so that by the end of Term 1 eight or more sounds have been taught). (pp. 11-14)

(Comment: Only eight letter-sounds in Term 1, vowels and consonants, are too few, because at the same time much 'reading' is done from lessons using 26 letters, and learnt by heart). 
Next the CAPS (2012b:15) gives the five main 'components of teaching reading' on which they say most reading professionals agree: Phonemic awareness, Word recognition, Comprehension, Vocabulary and Fluency, with the instruction that each should be taught clearly and practised daily. Phonemic awareness is explained as knowing that speech consists of sounds, recognising the individual sounds: 'how they make words and how these words can make sentences'.

Some activities for teaching phonemic awareness are activities that focus on rhyme, on syllable units, on onset and rime and on phonemes - e.g., Put these sounds together: ...

(Comment: The first and third of these 'activities' do not make sense in an African language, but translations are included in the CAPS for Sesotho HL; the last is very difficult.)

\section{Discussion of the above CAPS instructions for Grade 1 reading}

Giving 'Comprehension, Vocabulary and Fluency' as above, with the instruction that each should be practised daily, will not make a difference to what has been happening all along: no attention to comprehension, and seeming fluency only because children know lessons by heart. There is not much difference between what is instructed in the CAPS and what African teachers have been doing in the past: all reading together, then only groups or pairs reading together, over and over, as Rule and Land (2017:4) also reported the CAPS to be understood. Children can learn the lessons by heart without really reading, and just speak along. Something new is that the teacher should guide the reading of each group for 10-15 min each week, listening to individual reading also. However, what happens in practice is that most children know the lesson by heart before 'reading' to the teacher.

Important differences between African and European children when learning to read are that most European children receive assistance at home, and they are motivated to read because they grow up with books, unlike most township children in SA. The CAPS instructions are meant for European children, saying that some teachers give learners reading to do at home, which 'plays an important role in learning to read' (DBE 2012b:14).

\section{Evaluation of the ReSEP document: Teaching Reading (and Writing) in the Foundation Phase, published 2016}

The ReSEP document was compiled for pre-service and in-service training of Foundation Phase teachers, in 40 two-hour lectures.

Despite the training taking 80+ hours from a teacher's time, it will not help African teachers to teach reading. The basic problem is that the phonic approach is advocated and the syllabic approach not mentioned, and no new strategies for teaching reading indicated, for example, a strategy for much individual reading from early on, real reading. In ReSEP (Pretorius et al. 2016:9-11), the 'starting point' is that learners should know, about each letter, its alphabet name, its shape in lower and uppercase and the sound it represents.

(Comment: The problem with letter sounds has been mentioned: African children cannot say some single letters. Furthermore, letter names, and uppercase shapes, will add confusion.)

Moreover, the ReSEP document (Pretorius et al. 2016:9) holds that all teachers teaching reading should know the oral and written structure of English, Afrikaans and the African languages, know if and to which degree the writing code of each is transparent and how the phonics instruction is affected by the nature of the writing system. (Note the assumption that phonics instruction should be used for all languages.) The author thinks that taxing Grade 1 African teachers with knowledge about the structure of European languages, and how they should be taught as first languages, is to add madness to failure. (Teaching written ESL has no place in Grade 1 according to the CAPS for $E F A L$, as shown above.) Grade 1 teachers only need to know how to teach their own learners successfully and should specialise in this and stay in Grade 1 year after year, if successful according to the assessment of their learners. At present, some teachers take the same class from Grade 1 to 3 , meaning poor work is not exposed because that teacher is the only one assessing her learners for three years.

The ReSEP authors (2016:5) also held that although much research done on reading relates to English, they have made the necessary adaptations. Even though only a little research has been done on reading in African languages, they have amplified it with reading research in agglutinating languages such as Turkish, Basque and Finnish. However, Schaefer and De Vos (2015:4) wrote something that discredits the solution used by the ReSEP authors, namely that in Turkish final consonants of words are often manipulated. I want to indicate at this part of the ReSEP document that Turkish has final consonants and African languages not. Hence, research on Turkish is not the best for informing initial reading in African languages.

The ReSEP document (Pretorius et al. 2016:5) may also hamper reading in the HL by advancing written English in Grade 1, as the Lesson Plan for ESL does. The document says that as SA's education system is bilingual, children should become both bilingual and bi-literate and should develop robust literacy skills in both languages 'from the very beginning of schooling'. The authors do acknowledge that good reading skills in ESL depend on good HL reading ability, yet they want children to develop literacy skills in both languages simultaneously, without considering the confusion it may cause. They also seem not to know the best way for learning ESL, which is indicated by the CAPS for EFAL and not by the Lesson Plan for Grade 1.

This concludes a critique of educational documents, which was done to enlarge our picture of current language teaching in Grade 1 classrooms. 


\section{New methodology proposed for reading in Grade 1}

\section{Some present problems}

Grade 1 children are not only confused by great amounts of written English from Week 3 onwards, but even earlier by the written words accompanying lessons in every subject, for example, the written names of numbers up to 10, which in Sesotho have 14 more letters than in English. Children only learn to memorise what is written where, and soon learn to copy well from the board, as their books must bear witness that all work was covered. A great amount of such work is prescribed - far too much.

\section{Changes needed}

\section{Prioritise reading}

The main goal for Grade 1 should be that children learn to read the HL well and with understanding as quickly as possible. All other teaching should be subordinate to this goal and should not confuse children with letters and words other than those in a graded reading programme. It means that other subjects should be taught only orally for a period, for example the names of days, shapes, colours. English as a second language should be taught only orally for at least three terms. More than one reading session per day is needed, but as the time-consuming written work of other subjects falls away, time should be available.

\section{Use a new approach and new strategies}

The proposed new methodology requires that the wholelanguage approach combined with the syllabic approach and graded lessons are used. Firstly, children are taught the vowels and Strategy 1 for using a reference, the first reference being the five vowels $a, e, i, o, u$. To find the sound of a vowel, it should be matched to one in the reference and the reference recited up to the one needed. (Children find memorising and matching easy but tend to forget sounds.) The same strategy is later used for finding the sound of a syllable.

Strategy 2 is using 6-8 trained group leaders to give each group member many opportunities to read. The group leader moves a paper screen with a window cut in it over an A4 sheet, and every member reads what he can see through the window. First groups read single vowels, then mixed vowels, later sentences, then syllables. When children can 'read' the first eight sentences on the board - actually know them by heart - they read the mixed sentences on A4 sheets with the group leaders. (The sentences on the board serve as reference). This is real reading. The class teacher should first model the work of a group leader by taking one group at a time for reading vowels whilst the others practise writing. It will give the teacher the opportunity to identify, test and train leaders.

Strategy 3 is used when a sentence is read on the board: point with two fingers below a syllable having two letters, and with one finger below a syllable having one letter. This is also easy for children and helps them with segmenting.
Use new teaching materials, for example, A4 pages with mixed sentences

On Day 1 or 2, the first sentence is put on the board and read, for example in Sesotho 'mme o ama mimi' - 'Mother (she) touches Mimi'. All the sentences of Lesson 1 are put on the board during the first week and should remain in the same place until about $90 \%$ of learners can read mixed vowels and the mixed sentences of Lesson 1. The first Sesotho lessons have eight sentences each, written on the board as four pairs. Lesson 1 uses only $\mathrm{M}$ with the vowels. Lessons $2-5$ add one consonant each. Each further lesson adds more, and after about eight lessons only the DBE Workbook can be used. However, material for group-work should still be used, to prevent a falling back on just memorising lessons. The first lessons present sentences as pairs, in order to provide a context, even a little story as with these sentences from Lesson 2: 'leema o loma mimi. mme o oma leema.' - 'Leema bites Mimi. Mother threatens Leema.' The goal is reading for meaning, something which does not come from mechanical decoding of single words. However, single words should also be read, first on flashcards.

\section{Teachers' responsibilities}

The teacher moves amongst the groups whilst they read, checks on group leaders, and asks individuals questions on the sentence one has read, for example, 'What does mother do?' (The answer is not a repetition of the sentence, but: 'She touches Mimi'). Whilst children are still practising sentences, they are taught the syllables ' $m a, m e, m i, m o, m u$ ', and must read them when mixed. These five also stay up as reference. The references that should stay up for some weeks are the vowels, the sentence pairs of every lesson, the new syllables of that lesson, and later, the consonants in the order they were learnt: $m a, l a, n a, b a, k a, s a$, etc. for Sesotho. Strings with mixed consonants in syllables with '-a' should also be read and dictation tests written on them, to establish letter knowledge. Writing work should be confined to the letters being read already, but sufficient writing practice is important. Dictation should be started soon, for example, where children must write the vowel said by the teacher, and later words and sentences.

The group work is a solution for very large classes, and also allows for children learning to work together towards a common goal, viz. helping all members to get the reading right, not by giving a friend the answer, but by helping him to find the answer in a reference. The teacher should give much attention to her groups: appointing co-leaders, dividing slow learners equally amongst the groups, creating pride in achievement. Rules are: no talking in the rows, and no touching each other with any part of the body.

The proposed new methodology should have been put to the test in 2020, tested against the status quo, but the COVID-19 lockdown delayed it. In the next paragraph it will be compared to research already done in North West Province, to ask if the research described above is still needed. 


\section{Research done from 2015 in North West Province Methodology}

Taylor et al. (2017) reported on the first two years, 2015-2016, of a wide-ranging investigation in government schools in North West Province. They compared four groups of schools: about 50 schools on each of three interventions, and 80 control schools. All the schools received new learning materials that had no new strategies or anything not already in departmental documents; for example, shared reading and that letter-sound knowledge (phonics) are deemed especially important.

For Intervention 1, teachers received the learning materials mentioned, as well as a structured learning programme, lesson plans and 2 days' teacher training twice a year. For Intervention 2, teachers received the above, as well as 'a reading coach' who gave basic training regarding the lesson plans and new reading materials at the beginning of each term. This was followed by monthly on-site visits by coaches. The fact that the coaches observed classroom practice meant that teachers were more likely to use the training and prescriptions they had received, and it was the Intervention 2 group (Group 2) that received the best results. Intervention 3 was aimed only at involving parents but did not meet with success. Below are some results of Group 2.

\section{Some research findings in North West Province}

Letter recognition was part of data collection. At the end of Grade 1, 13\% of Group 2 learners from 50 schools scored zero on this item, and at the end of Grade 2, 8\% of learners scored zero. The result that only about $36 \%$ could read $50+$ letters correctly per minute at the end of Grade 2 (Taylor et al. 2017:67) is an indication that despite much attention to letter reading, children still found it difficult. Compare also the study by the ReSEP team at Stellenbosch University, where only $25 \%$ of 740 Grade 3 African learners could name 40+ letters correctly per minute (Spaull et al. 2017:15).

The fourth sub-test for Grade 2 in the North West intervention was paragraph reading, with four comprehension questions about the text. In the control group, 39\% of the children could not read one word correctly and in Group 2, 28\% could not read one word correctly, a difference of $11 \%$. In the comprehension test, $46 \%$ of control group children scored zero and $37 \%$ of Group 2 children scored zero, a 9\% improvement (Taylor et al. 2017:73-75). In general, an improvement of about $10 \%$ over the control group was found for Group 2. The author maintains that the intervention has not brought enough improvement, especially when considering the following:

In light of the fact that this intervention is intended to shift teaching practice and learning outcomes at a large scale, the magnitudes of the shifts in learning outcomes seen in the graphs above, though not miraculous, do appear substantial enough to warrant consideration for policy scale-up. (p. 75)

\section{Discussion of some results of the North West intervention}

If we compare the improvement of about $10 \%$ found in the North West intervention, to the information that in the 1990s it was found that about $80 \%$ of African children learnt to read in Grade 1, whilst at present only about $20 \%$ of such children learn to read in Grade 1, the intervention seems to have missed the target. In the light of the PIRLS 2016 test finding that only about $20 \%$ of SA Grade 4 have 'basic reading skills', an improvement of more than a $10 \%$ is necessary.

\section{Discussion of some results found by this study}

The literature review and information on features of African languages have brought new insights regarding some pedagogic causes of South Africa's reading crisis. One cause identified is that the approaches to initial reading in use are not suitable for African children and languages. Another pedagogic cause is that the DBE Lesson Plan, used for teaching ESL instead of the government's CAPS for EFAL, confuses children so much that most cannot learn to read. As a solution, a radical renewal of the Grade 1 curriculum was proposed. However, the drastic change that is necessary will only materialise if the DBE revises its prescriptions regarding initial reading in African languages, and its prescriptions for teaching ESL in Grade 1. This would require the academics advising authorities in Education to re-evaluate some of their assumptions about teaching initial reading in African languages, and their assumptions about teaching ESL at primary school.

\section{Recommendations for policy and practice}

For each of SA's African languages, new first reading courses should be developed along the lines explained, for example by using the syllabic approach and graded lessons consisting of meaningful sentences.

Teachers should receive training and materials for using new reading strategies, especially to use group leaders to provide much individual reading practice.

Care should be taken that children learn to read for meaning from the beginning, for example, teachers should ask individuals questions whenever they read in their groups.

Any instruction to use written ESL in Grade 1, for example the DBE Lesson Plan, should be withdrawn. Teachers should be convinced and taught to use only oral English in Grade 1, according to the CAPS for English FAL, so that learners can get a good foundation in HL reading, and also acquire sufficient levels of ESL.

\section{Conclusion}

Grave injustice has been done over many years to the majority of South African children, to the poor children who cannot 
learn ESL in expensive English crèches. Most of them are effectively kept ignorant by denying them the opportunity to learn to read in Grade 1, because they do not know that what they and their teachers consider to be 'reading', is simply memorising lessons and pretending to read.

\section{Acknowledgements}

The author would like to thank Prof. D.J. Postma, Department of Educational Foundations, UNISA.

\section{Competing interests}

The author declares that she has no financial or personal relationships that may have inappropriately influenced her in writing this research article.

\section{Author's contribution}

M.M.C. is the sole author of this article.

\section{Ethical consideration}

Ethical approval for this study was granted by the Ethics Review Committee on 19 February 2020 in compliance with the UNISA Policy on Research Ethics and the Standards Operating Procedure on Research Ethics Risk Assessment. Reference number: 2020/02/19/02811855/16/AM.

\section{Funding information}

This research received no specific grant from any funding agency in the public, commercial or not-for-profit sectors.

\section{Data availability}

The authors confirm that the data supporting the findings of this study are available within the article.

\section{Disclaimer}

The views and opinions expressed in this article are those of the author and do not necessarily reflect the official policy or position of any affiliated agency of the author.

\section{References}

Bamgbose, A., 2000, Language and exclusion: Consequences of language policies in Africa, Lit Verlag, Hamburg.

Barry, A., 2008, 'Reading the past: Historical antecedents to contemporary reading methods and materials', Reading Horizons: A Journal of Literacy and Language Arts 49(1), 31-52.

Cronje, M.M., 1997, 'The effect of different teaching methods on the acquisition of English as second language by black primary school children', Unpublished PhD thesis, University of the Free State.
Department of Basic Education (DBE), 2011, English first additional language lesson plans: Grade 1, viewed 04 August 2019, from https://nect.org.za/materials/psrip/ term-1/lesson-plans/psrip-gr-1-term-1-2020-efal-lesson-plan.pdf.

Department of Basic Education (DBE), 2012a, Curriculum and Assessment Policy Statement: Grades 1-3 English first additional language, viewed 02 October 2020, from https://www.education.gov.za/Portals/0/CD/National\%20Curriculum $\% 20$ Statements\%20and\%20Vocational/CAPS\%20ENGLISH\%2OFAL\%20GR\%201-3\%20 FS.pdf?ver=2015-01-27-155321-957.

Department of Basic Education (DBE), 2012b, Curriculum and Assessment Policy Statement (CAPS): Home languages, viewed 01 October 2020, from https://www. education.gov.za/Portals/0/CD/National\%20Curriculum\%20Statements\%20 and $\% 20$ Vocational/CAPS\%20English $\% 2$ HL $\% 20$ GRADES\%2OR-3\%2OFS. pdf?ver=2015-01-27-154201-167.

De Vos, M., Van der Merwe, K. \& Van der Mescht, C., 2014, 'A linguistic research programme for reading in African languages to underpin CAPS', Journal for Language Teaching 48(2), 148-177. https://doi.org/10.4314/jlt.v48i2.7

Draper, K. \& Spaull, N., 2015, 'Examining oral reading fluency among rural Grade 5 English Second Language (ESL) learners in South Africa: An analysis of NEEDU', South African Journal of Childhood Education 5(2), 44-77. https://doi. org/10.4102/sajce.v5i2.390

Fleisch, B., 2008, Primary education in crisis, Juta \& Co, Cape Town.

Howie, S., Combrinck, C., Roux, K., Tshele, M., Mokoena, G. \& McLeod, P., 2017, PIRLS literacy 2016: South African highlights report, viewed 01 October 2020, from http://hdl.handle.net/2263/66185.

Mlachila, M. \& Moeletsi, T., 2019, Struggling to make the grade: A review of the causes and consequences of the weak outcomes of South Africa's education system, IMF Working Paper No. 19/47, International Monetary Fund, Pretoria.

Perry, K.H., 2009, 'Primary school literacy in Southern Africa: African perspectives', Comparative Education 44(1), 57-73. https://doi.org/10.1080/03050 060701809433

Pretorius, E., Jackson, M., McKay, V., Murray, S. \& Spaull, N., 2016, 'Teaching reading (and writing) in the foundation phase', ReSEP, viewed 01 October 2020, from https://resep.sun.ac.za/wp-content/uploads/2017/10/RESEPp_Zenex-TeachingReadingWriting_Email.pdf.

Probert, T. \& De Vos, M., 2016, 'Word recognition strategies amongst isiXhosa/English bilingual learners: The interaction of orthography and language of learning and teaching', Reading \& Writing 7(1), 1-10. https://doi.org/10.4102/rw.v7i1.84

Rayner, K., Foorman, B., Perfetti, C., Pesetsky, D. \& Seidenberg, M.S., 2002, 'How should reading be taught?', Scientific American 286(3), 84-91. https:// doi:10.1038/scientificamerican0302-84

Reeves, C., Heugh, K., Prinsloo, C.H., Macdonald, C., Netshitangani, T., Alidou, H. et al., 2008, Evaluation of literacy teaching in the primary schools of the Limpopo Province, Report produced by the Human Sciences Research Council (HSRC) vrovince, Report produced by the Human Sciences Research Council (HSRC), v00.11910/4984.

Rule, P. \& Land, S., 2017, 'Finding the plot in South African reading education', Reading \& Writing 8(1), a121. https://doi.org/10.4102/rw.v8i1.121

Schaefer, M. \& De Vos, M., 2015, 'The development of phonological awareness literacy measures for isiXhosa', Southern African Linguistics and Applied Language Studies 33(3), 325-341. https://doi.org/10.2989/16073614.2015.1108769

Spaull, N. \& Hoadley, U., 2017, 'Getting reading right: Building firm foundations', South African Child Gauge 2017(Part 2), 77-83, viewed 03 October 2020, from http:// www.ci.uct.ac.za/sites/default/files/image_tool/images/367/Child_Gauge/ South African Child Gauge 2017/Child_Gauge_2017-Getting_reading_rightBuilding_firm_foundations.pdf.

Spaull, N. \& Pretorius, E., 2019, Still falling at the first hurdle: Examining early grade reading in South Africa, viewed 20 October 2019, from https://nicspaull.files. wordpress.com/2018/11/nic-spaull-and-elizabeth-pretorious.pdf.

Spaull, N., Pretorius, E. \& Mohohlwane, N., 2017, Investigating the comprehension iceberg: Developing empirical benchmarks for early grade reading in agglutinating African languages, viewed 20 October 2019, from https://2017.essa.org.za/ fullpaper/essa_3314.pdf.

Taylor, S., Cilliers, J., Prinsloo, C., Fleisch, B. \& Reddy, V., 2017, 'The early grade reading study: Impact evaluation after two years of interventions', EGRS Evaluation Report, viewed 03 October 2020, from https://www.jet.org.za/clearinghouse/ projects/primted/resources/language-and-literacy-resources-repository/egrstechnical-report-13-oct-2017.pdf.

Van der Berg, S., 2015, 'What the Annual National Assessments can tell us about learning deficits over the education system and the school career', South African Journal of Childhood Education 5(2), 28-43. https://doi.org/10.4102/sajce. v5i2.389

Williams, E., 1998, Investigating bilingual literacy: Evidence from Malawi and Zambia, Paper no. 24, Department for International Development, viewed 20 October 2019, from https://eric.ed.gov/?id=ED419222. 